\title{
Los procesos de catalogación y difusión de la información en el Museo Cerralbo de Madrid
}

\author{
Raquel Sardá Sánchez \\ María F. Sánchez Hernández \\ Universidad Rey Juan Carlos (España)
}

\section{Resumen}

Se presenta el proceso de digitalización y catalogación de los fondos del Museo Cerralbo de Madrid y los métodos empleados en su difusión. Su realización tuvo lugar dentro de un proyecto piloto lanzado por Red.es en colaboración con el Museo Cerralbo. Gracias a este proyecto de digitalización y catalogación se han establecido una serie de pautas para futuras digitalizaciones que Red.es pretende realizar en distintos museos. Al tratarse de un museo con una amplia variedad de objetos se ha podido detectar la problemática que plantean las distintas piezas en ambos procesos, catalogación y digitalización.

Palabras clave: Museo Cerralbo de Madrid (España). Digitalización. Catalogación. Red.es. Difusión. Documentación gráfica. Documentación textual.

\begin{abstract}
This paper describes the process of digitalization and cataloguing of the holdings of the Museum Carralbo (Madrid, Spain) and the different methods used for the publication and dissemination of its heritage. The research project was carried out by Red.es in cooperation with the museum. The project has been useful to establish a frame and guidelines for future digitalisation projects in the different museums where Red.es is involved, because of the variety of its holdings and its representativity.
\end{abstract}

Keywords: Cerralbo Museum (Madrid, Spain). Digitalization. Cataloguing. Red.es. Dissemination. Graphical documentation. Textual documentation.

\section{Introducción}

En 1946 se creó el Comité Internacional de Museos (ICOM) (Guinchat y Menou, 1992, p. 345), y aportó las primeras definiciones "oficiales" de museo recogidas en sus estatutos de 1947. Concretamente en el artículo 3 se reconoce la cualidad de museo a "toda institución permanente que conserva y presenta colecciones de objetos de carácter cultural o científico con fines de estudio, educación y deleite".

Scire. $14: 2$ (jul.-dic. 2008) 153-160. ISSN 1135-3716. 
En 1974 el ICOM ofrece una nueva definición en sus estatutos — que será ratificada por la Asamblea General celebrada en 1989-. En el artículo 4 considera que también forman parte de este los institutos de conservación y galerías de exposición dependientes de archivos y bibliotecas; los lugares y monumentos arqueológicos, etnográficos y naturales, y los sitios y monumentos históricos (Hernández, 1994, p. 69).

El Museo Cerralbo, ubicado entre las calles de Ferraz y Ventura Rodríguez de Madrid, nace por el afán coleccionista de la familia Cerralbo (Blanco, 1998; Jiménez, 1996; Navascués y Conde de Beroldingen, 1997, 1998ab y 2000; Vaquero, Jiménez y Lázaro, 2002). La mayoría de las obras que en él se conservan fueron adquiridas por Enrique de Aguilera y Gamboa, marqués de Cerralbo, debido al interés que sentía por la filantropía, la ciencia, la arqueología, la numismática, la pintura, las colecciones bibliográficas, etcétera.

Entre 1869 y 1900 Enrique de Aguilera y Gamboa y su familia realizaron numerosos viajes por España y por Europa y adquirieron una gran cantidad obras; en 1885 contaban con una gran colección, unas 50000 piezas aproximadamente. Su experiencia convirtió al marqués en un experto en arte, y su asesoramiento era solicitado por muchos amigos y conocidos del mundo artístico.

La catalogación de los fondos seleccionados como muestra para llevar a cabo el proyecto piloto de Red.es (Sardá y Sánchez, 2005) y su posterior digitalización se han realizado in situ aplicando distintos tratamientos técnicos y documentales a los fondos conservados en el Museo: fotografías, esculturas, dibujos, piezas numismáticas, pinturas, etcétera. Así mismo, se analizaron las dificultades y particularidades de las piezas que iban a ser catalogadas, digitalizadas y documentadas.

Los resultados reflejan cómo se fueron desarrollando los procesos de inventariado, selección, precatalogación, descripción de la infraestructura empleada y, por último, digitalización de los fondos más importantes.

\section{Metodología del proyecto: fase de análisis}

Las tareas fundamentales que formaron parte de este proceso fueron las siguientes:

Selección de piezas. Red.es y el Museo Cerralbo seleccionaron conjuntamente las piezas que se habían de digitalizar. Se eligieron objetos muy diferentes entre sí para poder obtener datos de la mayor cantidad posible de elementos artísticos (pinturas, muebles, esculturas, monedas, tapices, armas, artes decorativas, etcétera), que servirán para futuros proyectos de digitalización y catalogación.

Análisis previo. Se realizó un estudio de las piezas y materiales que se iban a digitalizar y catalogar, así como de su influencia en la fase de desarrollo: características físicas, ubicación, posible manipulación, particularidades de la superficie, etcétera. De este modo se determinaron las pautas para dicha digitalización.

Scire. 14 : 2 (jul.-dic. 2008) 153-160. ISSN 1135-3716. 
Requisitos para la digitalización y catalogación. En este estudio se evaluaron los elementos de digitalización de los materiales: número de tomas por pieza, resolución aconsejada, equipamiento, iluminación, etcétera.

Análisis del proceso de digitalización. Se incluyó una descripción del proceso completo, haciendo especial hincapié en la captura, la elaboración de pruebas, el control de calidad y la creación de másteres y derivados, entre otros.

Análisis del proceso de precatalogación y catalogación. Documento de identificación de piezas a partir del inventario facilitado por el Museo Cerralbo y definición de las pautas que se habían de seguir durante la fase de catalogación.

Recursos. Se recogen las recomendaciones y necesidades de los equipos y entornos de trabajo para llevar a cabo el proceso de digitalización.

\section{Listado de piezas seleccionadas para digitalizar y catalogar}

Por su idoneidad para el proyecto y la variedad de materiales, el personal del Museo estimó oportuno que la selección definitiva fuera la siguiente:

\begin{tabular}{|l|l|}
\hline Categoría & Objeto \\
\hline Dibujo & Coche barato y tapado. Dibujo a lápiz y carboncillo, Goya \\
\hline Fotografía & Foto. Revuelta de la Comuna de París, Charles Marville \\
\hline Armería. Armas defensivas & Celada de Emmanuel Filiberto de Saboya \\
\hline Muebles de asiento & Silla de manos \\
\hline Arnés de guerra & Arnés del Il marqués de Cerralbo \\
\hline Arnés de guerra & Arnés del conde de Alcudia \\
\hline Objetos de fumador & Purera \\
\hline Manuscrito & Libro de exequias de Isabel de Valois \\
\hline Pintura & San Francisco en éxtasis, El Greco \\
\hline Chimenea & Chimenea \\
\hline Pintura & Bodegón de Luis Meléndez \\
\hline Pintura & Puercoespines y víboras \\
\hline Pintura & Retrato de María de Médicis atribuido a Van Dyck \\
\hline Escritorios & Bureau de cilindro \\
\hline Cerámica. Arqueología & Ánfora \\
\hline Cerámica & Skyphos \\
\hline Escultura & Diana Cazadora \\
\hline Textiles. Tapices & Tapiz de Pastrana \\
\hline Relieve & Escudo de armas de Cerralbo y su esposa \\
\hline Objeto tridimensional & Copa de cerámica vidriada \\
\hline Textiles. Tapices & Tapiz de Bruselas \\
\hline Textiles. Tapices & Panoplia \\
\hline Muebles de asiento. Silla & Pareja de sillas neogóticas italianas \\
\hline
\end{tabular}

Scire. $14: 2$ (jul.-dic. 2008) 153-160. ISSN 1135-3716. 


\begin{tabular}{|c|c|}
\hline Categoría & Objeto \\
\hline Soportes. Columna & Capiteles de porcelana del Buen Retiro \\
\hline Collar & Collar de la Orden del Espíritu Santo \\
\hline Objeto decorativo & Pareja de jarrones de Meissen \\
\hline Muebles de asiento. Silla & Pareja de sillas con marquetería de flores \\
\hline Mesas & Mesa ebanizada con marquetería de hueso (mesa florentina) \\
\hline Relojes & Reloj de órgano \\
\hline Objetos decorativos & Jarrón de piedras duras \\
\hline Escultura & Busto \\
\hline Pintura & La Piedad, Alonso Cano \\
\hline Pintura & Jacob con los corderos de Labán, José de Ribera \\
\hline Pintura & Inmaculada Concepción, Francisco de Zurbarán \\
\hline Medalla & De proclamación de Isabel II en Valencia \\
\hline Medalla & Conmemorativa Francesa de Luis XVIII, octogonal, plata \\
\hline Medalla & Del papa Clemente XI, 1704, dorada \\
\hline Medalla & Conmemorativa de Fernando VI \\
\hline Moneda & Cuadrante con semiuncia \\
\hline Moneda & Didracma griego de plata \\
\hline Moneda & Tremis visigodo de oro \\
\hline Moneda & Taller alemán de 1613 \\
\hline Moneda & Ocho reales de Lima \\
\hline \multirow[t]{2}{*}{ Moneda } & Ocho reales de Felipe III de plata \\
\hline & Papel amarillo \\
\hline Relojes & Reloj misterioso \\
\hline Objetos de iluminación & Pareja de candelabros estilo Luis XVI \\
\hline Escultura & Escultura de bronce \\
\hline Muebles de asiento. Silla & Silla \\
\hline Escultura & Busto \\
\hline Muebles de asiento. Sillón & Butaca \\
\hline Objetos de iluminación & Lámpara de techo \\
\hline Pintura & Retrato de Agustino Doria, Tintoretto \\
\hline Pintura & Retrato de Adam de Coster, Van Dyck \\
\hline Pintura & Retrato de niño atribuido a Zurbarán \\
\hline Pintura & Retrato de caballero atribuido a Ranc \\
\hline Mesas & Mesa de billar, siglo XIX \\
\hline Objetos de iluminación & Lámpara veneciana \\
\hline Objetos decorativos. Jarrón & Conjunto de dos jarras de porcelana de Meissen \\
\hline Escultura & Tondo del taller Della Robbia \\
\hline
\end{tabular}

Tabla I. Piezas seleccionadas agrupadas por categorías para su digitalización. 


\section{Fase de catalogación de las piezas}

Los procesos de catalogación y documentación de las distintas piezas, así como de los activos digitales generados, fue un proceso largo y complejo que se abordó en distintas fases.

La catalogación de las piezas la realizaron diferentes expertos en cada una de las materias tratadas (numismática, artes decorativas, armas, arqueología, etcétera), teniendo en cuenta las indicaciones tanto del Museo Cerralbo como de Red.es. Estos expertos (historiadores del arte, documentalistas, etcétera) realizaron dos tipos de ficha descriptiva de cada obra: $a$ ) una orientada a usuarios especializados y expertos, en la que se hace una descripción completa de cada pieza, con aportación de bibliografía para ampliar información (en aquellos casos en los que se consideró apropiado), enlaces a webs de interés, identificación de piezas relacionadas en otros museos, etcétera; $b$ ) otra de carácter divulgativo, resumida y adaptada con un enfoque pedagógico, orientada a todos los usuarios y con un fin educativo.

El contenido de estas fichas se estructuró posteriormente siguiendo los campos del software DOMUS, un sistema integrado de documentación y gestión museográfica cuyos principales objetivos son la normalización de elementos documentales, los procesos de gestión museográfica y el control terminológico. Fue desarrollado por el Ministerio de Educación, Cultura y Deporte (MECD) en 1993. Se utiliza en los museos titularidad estatal y lo gestiona exclusivamente la Administración General del Estado a través de la Subdirección General de Museos Estatales de la Dirección General de Bellas Artes y Bienes Culturales.

Para realizar la catalogación de los activos digitales se realizó un prototipo de base de datos que permitía transmitir información siguiendo esquemas XML: 1) información descriptiva para exportar los datos necesarios al estándar Dublin Core; 2) información administrativa sobre los activos digitales y su preservación siguiendo los esquemas METS especificados previamente, tomados del prototipo audiovisual de la Biblioteca del Congreso.

\subsection{Dublin Core}

Dublin Core es un estándar abierto de metadatos que se utiliza para describir todo tipo de objetos con el fin de facilitar una manera sencilla de interactuar y acceder a esos datos de forma automática.

Este estándar tomó su nombre de Dublín, ciudad ubicada en Ohio (Estados Unidos), que en 1995 fue sede de la primera reunión de ámbito mundial de muchos de los especialistas en metadatos y Web de la época.

Este formato de metadatos es el más conocido y extendido, especialmente en el ámbito de la biblioteconomía y la documentación. Se creó para ofrecer un estándar general, sencillo y descriptivo de los documentos web de cualquier ámbito 
o materia. Dublin Core ofrece 15 elementos opcionales y repetibles que permiten describir el contenido del documento digital.

La información descriptiva de las piezas del museo se realizó utilizando el estándar Dublin Core, que está ampliamente documentado aunque no se utiliza específicamente para catalogar objetos museísticos; por ello muchos datos no pueden adaptarse a los campos utilizados por este estándar, ya que se usa más para otro tipo de datos, como es el caso de los bibliográficos, que habitualmente están localizados y fechados. En el caso de las piezas de museo a veces no se cuenta con una fecha o lugar concreto de creación, sino que se dispone de datos aproximados. Por otra parte, Dublin Core tiene campos y especificaciones relativos a publicaciones y autorías, etcétera, que no se aplican en el caso de piezas museísticas.

Los objetos de los museos que están catalogados bajo DOMUS cuentan con campos y sistemas de clasificación específicos que se pueden aplicar a estos objetos, por lo que en algunos momentos resultó difícil compatibilizar ambos sistemas. Con el fin de no perder información por este motivo, la descripción generada por los especialistas del museo, en la que se siguió la estructura del programa DOMUS, se aglutinó para incluirla en los campos generales de Dublin Core. Es el caso del campo descripción de Dublin Core, donde se ha agrupado cierta información que en DOMUS tiene un tratamiento específico y diferenciado; por ejemplo, historia del objeto, contexto cultural, iconografía, firmas y marcas, uso y función.

\subsection{METS}

METS schema (Metadata Encoding \& Transmission Standard) facilita un prototipo para codificar metadatos descriptivos, administrativos y estructurales referidos a objetos dentro de la biblioteca digital.

Para la catalogación de campos administrativos de METS se ha seguido el prototipo de la Biblioteca del Congreso, que no es un estándar en sí mismo, y por tanto no existe demasiada información complementaria. Este prototipo es una iniciativa de la Federación de Bibliotecas Digitales. La falta de documentación ha generado grandes dificultades en la creación de los datos requeridos. A esto se añade la ausencia de manuales o ejemplos que sirvan de referencia. Además, los distintos campos seleccionados para la documentación técnica sobre los activos son bastante complejos y exigen un gran nivel de especialización de los expertos catalogadores, teniendo en cuenta que no existen guías de cumplimentación de la información solicitada.

\subsection{DOMUS}

Este programa permite registrar, inventariar y catalogar fondos museográficos y documentales; controlar los procesos de gestión que sufre un fondo a lo largo de su secuencia vital en el museo; asociar imágenes digitales en procesos de catalo- 
gación y conservación; regular y gestionar dichas imágenes y las reproducciones de los fondos.

Actualmente está implantado en diferentes museos de titularidad estatal. Además se está tramitando, vía convenio de colaboración, su establecimiento en algunas comunidades autónomas y en museos de otra titularidad, con el objeto de constituir un catálogo colectivo de museos que se integrará, en el futuro, en el Catálogo del Patrimonio Histórico Español.

El MECD se compromete a desarrollar los módulos necesarios que permitan una traducción de la aplicación DOMUS del castellano a las lenguas oficiales de las comunidades autónomas interesadas en disponer de versiones en otras lenguas, así como a establecer relaciones de equivalencia lingüística entre los términos normalizados en tesauros.

Debido a que el Museo Cerralbo ya había iniciado la catalogación de sus fondos siguiendo el esquema de DOMUS, en el desarrollo de este proyecto piloto, iniciativa de Red.es, se ha procedido a estructurar las fichas generadas siguiendo los campos que marcan el sistema para poder darlas de alta en el mismo. También se ha utilizado para la unificación de los procesos de catalogación y tratamiento técnico de los fondos museográficos, documentales y administrativos del museo, la unificación de vocabularios, tesauros, etcétera — tan necesarios para alcanzar la máxima eficacia y rentabilidad de su sistema documental—, así como para el intercambio de información con otros museos, ya que permite compartir datos y difundirlos a través de las redes de telecomunicaciones mediante el Catálogo Colectivo.

\section{Conclusiones}

Los museos son lugares donde se reúnen objetos que presentan un interés histórico, científico, técnico o artístico. Su finalidad primordial es la difusión de sus fondos, para acercarlos tanto a usuarios académicos — expertos e investigadorescomo a un público general.

Con este estudio hemos comprobado que para abordar la catalogación y documentación de piezas tan diversas, donde la información con la que se cuenta como punto de partida es prácticamente nula, es necesario colaborar con catalogadores e historiadores del arte muy especializados en una materia concreta. Este hecho dificulta el proceso de catalogación, ya que hace que el número de personas que participan en el proyecto tenga que ser muy elevado. En cualquier caso, se recomienda que sea el propio museo el que facilite el contacto con estos historiadores del arte y especialistas, ya que habitualmente son personas que colaboran con ellos.

En el caso de numerosos museos y colecciones únicamente se conserva un inventario o listado de obras y no existe información adicional de la pieza: datación, autoría, etcétera. Esta ausencia de documentación e información repercute en que Scire. 14 : 2 (jul.-dic. 2008) 153-160. ISSN 1135-3716. 
se debe hacer un análisis muy estricto y preciso de los fondos, ya que los datos obtenidos, con toda seguridad, se convertirán en la primera catalogación de la pieza y, por tanto, en la información base para futuras investigaciones.

La falta de estándares definidos y únicos, unida a la escasa documentación existente en materia de catalogación de piezas museísticas, dificulta el proceso global de catalogación de las mismas y en ocasiones nos obliga a tomar decisiones sin contar con guías o ejemplos ya existentes, por lo que se debe insistir en la necesidad de conseguir una normalización aplicada a determinados procesos.

Debido a que el contenido de una ficha catalográfica puede resultar complejo para el público general, especialmente para los estudiantes, es recomendable adaptar el texto y ofrecer una descripción divulgativa para que todos los usuarios tengan acceso a la información y a la vez puedan ser partícipes de un legado artístico que es de todos.

\section{Referencias}

Blanco Conde, M. (1998). Salón Árabe. Palacio Marqués de Cerralbo. Madrid: Ministerio de Educación y Cultura, 1998.

Guinchat, C.; Menou, M. (1992). Introducción general a las ciencias y técnicas de la información y documentación. Madrid: CINDOC, 1992.

Hernández Hernández, F. (1994). Manual de museología. Madrid: Síntesis, 1994.

Jiménez Sanz, C. (1996). Pioneros: Enrique de Aguilera y Gamboa, marqués de Cerralbo. // Revista de Arqueología. 182 (1996) 52-57.

Mellén Blanco, F. (2002). Armas de Nueva Caledonia en el Museo Cerralbo de Madrid. Madrid: s. n., 2002.

Museo Cerralbo de Madrid. http://museocerralbo.mcu.es/ (2006-05-12).

Navascués Benlloch, P. de; Conde de Beroldingen Geyr, C. (1997). Museo Cerralbo. Madrid: Ministerio de Educación y Cultura, 1997.

Navascués Benlloch, P. de; Conde de Beroldingen Geyr, C. (1998a). D. Enrique de Aguilera y Gamboa, coleccionista y fundador del Museo del Marqués de Cerralbo. // Goya. 267 (nov.-dic. 1998) 323-332.

Navascués Benlloch, P. de; Conde de Beroldingen Geyr, C. (1998b). El legado de un mecenas. Pintura española del Museo Marqués de Cerralbo. Madrid: Ministerio de Educación y Cultura, 1998.

Navascués Benlloch, P. de; Conde de Beroldingen Geyr, C. (2000).

Museo Cerralbo. Madrid: Electa / Ministerio de Educación, Cultura y Deporte ("Guías Artísticas Electa"), 2000.

Sardá Sánchez, R. (2005); Sánchez Hernández, M. ․ F. (2005). El Museo Cerralbo de Madrid: desde sus orígenes a la digitalización de sus fondos. // IV Jornadas sobre imagen cultura y tecnología. Madrid: Universidad Carlos III, 2005.

Vaquero Argüelles, L.; Jiménez Sanz, C.; Lázaro Martínez, A. (2002). ÁLBUM. La colección de fotografía del marqués de Cerralbo. Madrid: Ministerio de Educación, Cultura y Deporte, 2002. 